\title{
Maternal and fetal outcome in oligohydramnios: study from a tertiary care hospital, Ahmedabad, India
}

\author{
Runoo Ghosh ${ }^{1 *}$, Heena Oza², Bhakti Padhiyar² \\ ${ }^{1}$ Department of Obstetrics and Gynecology, GMERS Medical College, Gandhinagar, Gujarat, India
}

${ }^{2}$ Department of Obstetrics and Gynecology, B. J. Medical College, Ahmedabad, Gujarat, India

Received: 13 June 2017

Accepted: 08 July 2017

*Correspondence:

Dr. Runoo Ghosh,

E-mail: drrunoog@gmail.com

Copyright: ( $\odot$ the author(s), publisher and licensee Medip Academy. This is an open-access article distributed under the terms of the Creative Commons Attribution Non-Commercial License, which permits unrestricted non-commercial use, distribution, and reproduction in any medium, provided the original work is properly cited.

\begin{abstract}
Background: Most severe and frequent complication of pregnancy is Oligohydramnios and the incidence of this is observed to be about 1-5\% of total pregnancies. Objective of present study was to find the maternal and perinatal outcome, etiology associated with oligohydramnios at tertiary care hospital.

Methods: This prospective study was done among 55 patients with gestational age from 30-40wks with Oligohydramnios AFI $55 \mathrm{cms}$ with intact membranes were analysed for perinatal outcomes admitted at department of obstetrics and Gynecology in B.J. Medical college, Ahmedabad during November 2011 to January 2013.

Results: $65.5 \%$ participants were belonged to 20 to 25 age group and $35.5 \%$ participants were Primigravida. Mean age was $23.9 \pm 3.3$ years and mean gestation age was 36.9 week. Almost $72.2 \%$ were in 34 to 37 weeks of gestational age. Study found FMC $<10$ in $56.4 \%$ of participants. Forty percent participants have AFI 4 and $27.3 \%$ have AFI 5 . $47.3 \%$ delivery was done by vaginal route. $5.5 \%$ baby was still birth and prematurity were the most common cause of still birth. Around $71 \%$ babies were low birth weight and congenital anomalies were present in $7.3 \%$ babies. APGAR score measured $<7$ at 1 minute was in $65.4 \%$ and $<7$ at 5 minutes was in $43.6 \%$ babies.

Conclusions: Oligohydramnios in obstetrics is a frequent occurrence and it points towards intensive surveillance and proper ante-natal and post-natal care. Due to high perinatal morbidity and mortality, the incidence of LSCS increases. However, vaginal delivery has similar outcome, but strict vigilance in labor is mandatory.
\end{abstract}

Keywords: AFI, LSCS, Oligohydramnios, Maternal outcome, Perinatal outcome

\section{INTRODUCTION}

During antenatal fetal surveillance, amniotic fluid assessment is a crucial barometer to know the fetal status. ${ }^{1}$ Primal sonographic sign of an obstetrical issue is abnormal amniotic fluid volume. ${ }^{2}$

Normally during third trimester, around $3 \%$ to $8 \%$ of pregnant women are anguishing from low amniotic fluid at any point of pregnancy. It is normally anticipated as a sign of placental insufficiency. ${ }^{3}$ Most severe and frequent complication of pregnancy is Oligohydramnios and the incidence of this is observed to be about $1-5 \%$ of total pregnancies. ${ }^{4}$ Associate congenital fetal abnormalities with oligohydramnios are uteroplacental insufficiency, premature rupture of membranes, growth retardation, postterm pregnancy, chronic abruption placentae. ${ }^{1}$

Compression of uterine wall and adherent fetal parts and prolonged external compression and abnormal fetal development due to prolonged Oligohydramnios boost the risk of pulmonary hypoplasia includes fetal skeletal 
and facial deformities. Oligohydramnios also increase the caesarian section rate for fetal distress up to $41 \% .{ }^{5}$ It also escalate the maternal morbidity and mortality by maternal complications like inertia, increased operative interference due to malpresentation ultimately. ${ }^{1,5}$

So, this study was conducted with objectives to find the maternal and perinatal outcome, etiology associated with oligohydramnios at tertiary care hospital.

\section{METHODS}

This prospective study was done among 55 patients with gestational age from 30-40wks with Oligohydramnios AFI $<5 \mathrm{cms}$ with intact membranes were analysed for perinatal outcomes admitted at department of obstetrics and Gynecology in B. J. Medical college, Ahmedabad during November 2011 to January 2013. Data collection was done after ethical permission from institutional ethical committee and informed consent of participants.

\section{Inclusion criteria}

Inclusion criteria for present study were women with singleton, non-anomalous fetus with intact membranes and gestational age 30-40 weeks.

\section{Exclusion criteria}

Exclusion criteria were women with premature rupture of membranes, known fetal and chromosomal anomaly, severe pre-eclampsia, posterm pregnancyetc.

Information regarding antenatal and postnatal history, clinical examination, laboratory investigations was noted on admission.

\section{Oligohydramnios}

When the maximum vertical pocket of liquor is less than $2 \mathrm{~cm}$ or when amniotic fluid index (AFI) is less than 5 $\mathrm{cm}$. AFI $5-8 \mathrm{~cm}$ as borderline oligohydramnios and AFI $8-18 \mathrm{~cm}$ as normal amniotic fluid index. ${ }^{6}$

\section{Amniotic fluid index technique}

Patient placed in supine position and a linear, curvilinear or sector transducer used. Maternal abdomen is divided into quadrants taking the umbilicus, symphysis pubis and the fundus as the reference points. With ultrasound, the largest vertical pocket in each quadrant is measured. The sum of the four measurements $(\mathrm{cm})$ is the AFI. ${ }^{7}$

\section{RESULTS}

Table 1 shows that $65.5 \%$ participants were belonged to 20 to 25 age group and $35.5 \%$ participants were Primigravida. Mean age was $23.9 \pm 3.3$ years and mean gestation age was 36.9 week. Almost $72.2 \%$ were in 34 to 37 week of gestational age. study found FMC $<10$ in
$56.4 \%$ of participants. Forty percent participants have AFI 4 and $27.3 \%$ have AFI 5.

Table 1: Clinico-social parameters of participants $(\mathrm{N}=55)$.

\begin{tabular}{|ll|}
\hline Parameters & Number $(\%)$ \\
\hline Age group & \\
\hline $20-25$ & $36(65.5)$ \\
\hline $26-30$ & $13(23.6)$ \\
\hline$>30$ & $6(10.9)$ \\
\hline Mean age (Mean \pm SD) & $23.9 \pm 3.3$ \\
\hline Parity & \\
\hline Primigravida & $19(35.5)$ \\
\hline Multigravida & $36(65.5)$ \\
\hline Gestational age (in week) & \\
\hline $30-34$ & $7(12.7)$ \\
\hline $34-37$ & $40(72.7)$ \\
\hline $37-40$ & $8(14.6)$ \\
\hline Mean age (Mean \pm SD) & $36.9 \pm 2.5$ \\
\hline FMC & \\
\hline$<10$ & $31(56.4)$ \\
\hline$\geq 10$ & $24(43.6)$ \\
\hline AFI on admission & \\
\hline 0 & $1(1.8)$ \\
\hline 1 & $3(5.5)$ \\
\hline 2 & $8(14.5)$ \\
\hline 3 & $6(10.9)$ \\
\hline 4 & $22(40.0)$ \\
\hline 5 & $15(27.3)$ \\
\hline FC-Fetal & \\
\hline
\end{tabular}

FMC-Fetal movement counting, SD-Standard deviation, AFIAmniotic fluid index

Figure 1 shows NST was non-reactive in $52.7 \%$ participants.

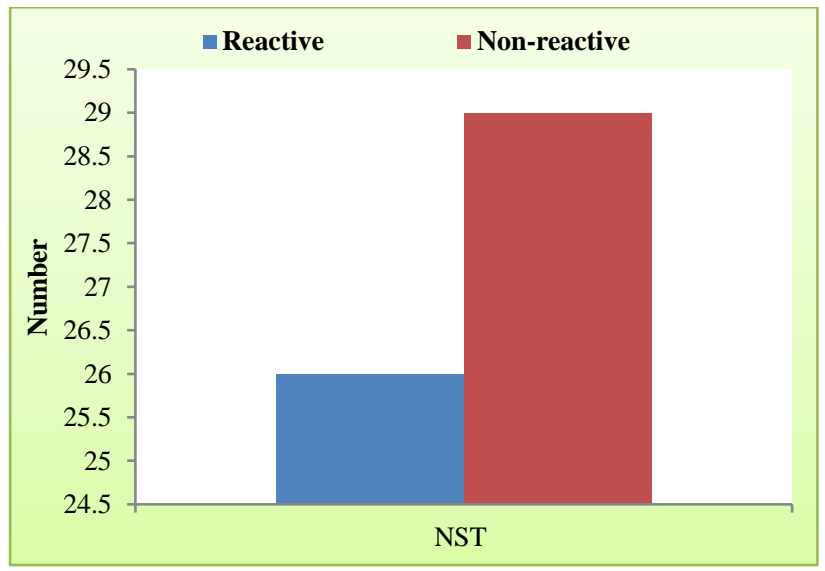

NST-Non-stress Test

Figure 1: Distribution of NST pattern in patients with oligohydramnios $(\mathrm{N}=55)$.

Figure 2 shows that abnormal Doppler ultrasound in the form of decreased diastolic flow I umbilical artery or increased diastolic flow in middle cerebral artery found in $21.8 \%$ participants. 


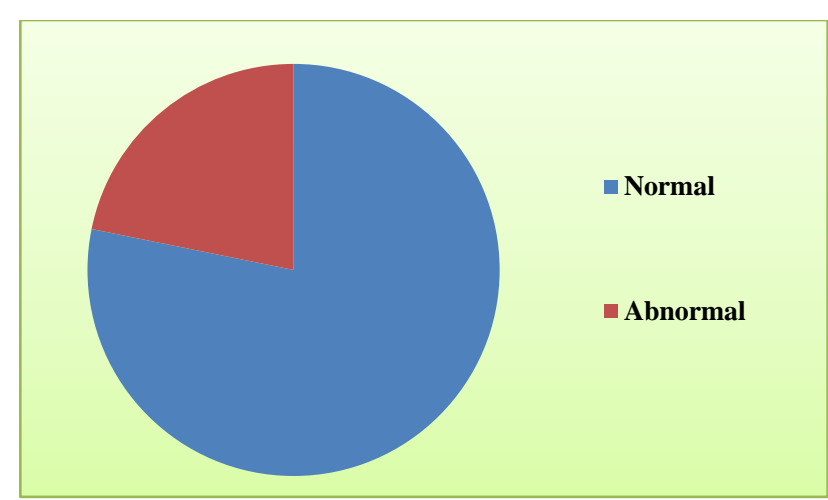

Figure 2: Findings of Doppler ultrasound $(\mathrm{N}=55)$.

Table 2 shows that $47.3 \%$ delivery was done by vaginal route and small for gestational age (SGA) was found in $45.5 \%$ participants.

Almost 5.5\% baby was Still birth and prematurity was the most common cause of still birth. Around $71 \%$ babies were low birth weight and congenital anomalies were present in $7.3 \%$ babies. APGAR score measured $<7$ at 1 minute was in $65.4 \%$ and $<7$ at 5 minutes was in $43.6 \%$ babies.

Table 2: Maternal and perinatal outcome in patients with oligohydramnios $(\mathrm{N}=55)$.

\begin{tabular}{|c|c|}
\hline Outcome & Number (\%) \\
\hline \multicolumn{2}{|c|}{ Mode of delivery } \\
\hline Vaginal & $26(47.3)$ \\
\hline Instrumental & $2(3.6)$ \\
\hline LSCS & $27(49.1)$ \\
\hline \multicolumn{2}{|l|}{ IUGR } \\
\hline AGA & $30(54.5)$ \\
\hline SGA & $25(45.5)$ \\
\hline \multicolumn{2}{|c|}{ Birth outcome } \\
\hline Live Birth & $52(94.5)$ \\
\hline Still Birth & $3(5.5)$ \\
\hline \multicolumn{2}{|c|}{ Cause of death $(n=3)$} \\
\hline Prematurity & 3 \\
\hline HMD & 1 \\
\hline Septicemia & 2 \\
\hline MAS & 1 \\
\hline \multicolumn{2}{|c|}{ Birth weight (Kg) } \\
\hline$<2.5$ & $39(70.9)$ \\
\hline$\geq 2.5$ & $16(29.1)$ \\
\hline \multicolumn{2}{|c|}{ Congenital anomalies } \\
\hline Present & $4(7.3)$ \\
\hline Absent & $51(92.7)$ \\
\hline \multicolumn{2}{|l|}{ APGAR score } \\
\hline 1 minute $<7$ & $36(65.4)$ \\
\hline 5 minute $<7$ & $24(43.6)$ \\
\hline $\begin{array}{l}\text { LSCS-Lower se } \\
\text { growth retardatio } \\
\text { Small for gestat } \\
\text { MAS-Muconium }\end{array}$ & $\begin{array}{l}\text { section, IUGR-Intra-uterine } \\
\text { riate for gestational age, SGA- } \\
\text { D-hyaline membrane disease, } \\
\text { ome. }\end{array}$ \\
\hline
\end{tabular}

\section{DISCUSSION}

Women who are at risk for potentially adverse perinatal outcome can be identified by the assessment of amniotic fluid volume in antenatal period. ${ }^{6}$

Mean age of participants was 23.9 years and mean gestational age was 36.9 years found in present study. Similar study done by Biradar KD et al, Vidyasagar V et al, Jagatia $\mathrm{K}$ et al and Bhat $\mathrm{S}$ et al were also found similar finding of mean age..$^{7-10}$ Almost $65.5 \%$ participants were belonged to 20 to 25 years age group in present study. These findings are comparable with the study done by Biradar KD et al, Patel PK et al but contrast result was found in study done by Vidyasagar et al $(80.49 \%){ }^{7,8,11}$ Almost $35.5 \%$ participants were Primigravida. In similar study done by Biradar et al, Vidyasagar et al and Patel RK et al, where Primigravida participants were $33.0 \%$, $46.3 \%$ and $35.8 \%$ respectively. ${ }^{7,8,11}$

Incidence of Pelvic inflammatory disease (Pregnancy induced hypertension- PIH) in present study was $34.5 \%$ and this finding is not comparable with similar study done by Biradar et al $(24.4 \%){ }^{7}$ About $49.1 \%$ deliveries were done by LSCS. Similar study done by Biradar et $\mathrm{al}^{7}$, Patel PK et al, Bangal VB et al, Sowmya K et al, Bansal $\mathrm{D}$ et al, Casey B et al and Golan et al found LSCS incidence in $62.0 \%, 41.0 \%, 44.0 \%, 50.0 \%, 47.0 \%, 32.0 \%$ and $35.2 \%$ respectively. ${ }^{1,5,11-14}$ Around $70.9 \%$ babies were found low birth weight in our study which is comparable with similar study done by Patel RK et al and contrast result was found in study done by Biradar et al $(38.6 \%))^{7,11}$ In present study, APGAR score $<7$ at 1 minute and $<7$ at 5 minute in $65.4 \%$ and $43.6 \%$ babies respectively. Similar study done by Biradar et al, Patel PK et al, Vidyasagar V et al, Casey B et al, Sriya V et al and Zhang $\mathrm{J}$ et al found APGAR score $<7$ at 1 minute in $26.0 \%, 34.6 \%, 35.0 \%, 6.0 \%, 38.8 \%$ and $13.3 \%$ respectively. $., 7,8,11,15,16$

To identify women who need increased antepartum surveillance for pregnancy complications, Antepartum measurement of AFI can very much helpful. ${ }^{17}$ Borderline AFI group, the presence of abnormal Doppler velocimetry measurement with borderline AFI was concerned to adverse perinatal. ${ }^{18}$ Present study observed AFI $\geq 4$ in $67.3 \%$ and FMC $<10$ in $56.4 \%$ participants which is comparable with the findings of study done by Chaudhary KR et al. ${ }^{18}$

\section{CONCLUSION}

Oligohydramnios in obstetrics is a frequent occurrence and it points towards intensive surveillance and proper ante-natal and post-natal care. Due to high perinatal morbidity and mortality, the incidence of LSCS increases. However, vaginal delivery has similar outcome, but strict vigilance in labor is mandatory. The presence of any other risk factor with oligohydramnios increases the chances of cesarean delivery. 
Oligohydramnios is significantly associated with abnormal fetal growth and IUGR. So timely intervention by an obstetrician will be help in improving the perinatal outcome.

\section{Funding: No funding sources}

Conflict of interest: None declared

Ethical approval: The study was approved by the Institutional Ethics Committee

\section{REFERENCES}

1. Bansal D, Deodhar P. A clinical study of maternal and perinatal outcome in oligohydramnios. J Res Med Den Sci. 2015;3(4):312-6.

2. Williams Obstetrics. Cunningham FG, Gant NF, Leveno KJ, Gilstrap LC III, Hauth JC, Wenstrom KD: 21st Edition USA; McGraw Hill. Fetal Growth and Development. Chapter 7:142-3.

3. Gaikwad PR, Oswal MS, Gandhewar MR, Bhatiyani BR. Perinatal outcome in oligohydramnios and borderline amniotic fluid index: a comparative study. Int J Reprod Contracept Obstet Gynecol. 2016;5:1964-8.

4. Moore TR. Clinical assessment of amniotic fluid. Clin Obstet Gynaecol. 1997;40(2):303-13.

5. Casey BM, McIntire DD, Bloom SL, Lucas MJ, Santos R, Twickler DM, et al. Pregnancy outcomes after antepartum diagnosis of oligohydramnios at or beyond 34 weeks of gestation. Am J Obstet Gynecol. 2000;182(4):909-12.

6. Phelan JP, Ahn MO. Amniotic fluid measurements during pregnancy. J Reprod Med. 1987;32:601-4.

7. Biradar KD, Shamanewadi AN. Maternal and perinatal outcome in oligohydramnios: study from a tertiary care hospital, Bangalore, Karnataka, India. Int J Reprod Contracept Obstet Gynecol. 2016;5:2291-4.

8. Vidyasagar V, Chutani N. Fetomaternal outcome in cases of oligohydramnios after 28 weeks of pregnancy. Int J Reprod Contracept Obstet Gynecol. 2015;4:152-6.
9. Jagatia K, Singh N, Patel S. Maternal and fetal outcome in oligohydramnios: a study of 100 cases. Int J Med Sci Public Health. 2013;2:724-7.

10. Bhat S, Kulkarni V. Study of effect of oligohydramnios on maternal and fetal outcome. Int J Med and Dent Sci. 2015;4(1):582-8.

11. Patel PK, Pitre DS, Gupta H. Pregnancy outcome in isolated oligohydramnios at term. Ntl J Commun Med. 2015;6(2):84-8.

12. Bangal VB, Giri PA, Sali BM. Incidence of oligohydramnios during pregnancy and its effects on maternal and perinatal outcome. J Pharmaceut Biomed Sci. 2011;12(05):1 -4.

13. Sowmya K, Varghese B, Borkar YB. Effect of isolated oligohydramnios in otherwise normal term pregnancy. Int J Biomed Res. 2014;5(2):98-101.

14. Golan A, Lin G, Evron S, Arieli S, Niv D, David MP. Oligohydramnios: maternal complications and fetal outcome in 145 cases. Gynecol Obstet Invest. 1994;37(2):91 -5.

15. Sriya R, Singhai S. Perinatal outcome in patients with amniotic fluid index $<5 \mathrm{~cm}$. J Obstet Gynaecol India. 2001;51:98-100.

16. Jun Zhang, Troendle J, Meikle S, Klebanoff MA, Rayburn WF. Isolated oligohydramnios is not associated with adverse perinatal outcome. BJOG. 2004;111(3):220-5.

17. Chauhan SP, Sanderson M. Perinatal outcome and amniotic fluid index in the antepartum and intrapartum periods: a meta-analysis. Am J Obstet Gynecol. 1999;181(6):1473-8.

18. Chaudhari KR, Chaudhari KR, Desai OM. Perinatal outcome associated with oligohydramnios in third trimester. Int J Reprod Contracept Obstet Gynecol. 2017;6:72-5.

Cite this article as: Ghosh R, Oza H, Padhiyar B. Maternal and fetal outcome in oligohydramnios: study from a tertiary care hospital, Ahmedabad, India. Int J Reprod Contracept Obstet Gynecol 2018;7:907-10. 